\title{
VULNERABILIDADE E \\ ATO INFRACIONAL: O \\ NOVO LÉXICO JUDICIAL \\ PARA A LEGITIMAÇÃO DO ENCARCERAMENTO DE \\ ADOLESCENTES NO BRASIL
}

VULNERABILITY AND YOUTH CRIME: THE NEW LEXICON FOR THE LEGITIMIZATION OF IMPRISONMENT OF TEENAGERS IN BRAZIL

VULNERABILIDAD Y ACTO INFRACCIONAL: EL NUEVO LÉXICO JUDICIAL PARA LA LEGITIMACIÓN DEL ENCARCELAMIENTO DE ADOLESCENTES EN BRASIL

Marília de Nardin Budó ${ }^{1}$

1 Professora do Programa de pós-graduação em direito da Faculdade Meridional (IMED-Passo FundoRS). Doutora em direito pela Universidade Federal do Paraná. Mestre em direito pela Universidade Federal de Santa Catarina. Especialista em Pensamento político brasileiro pela Universidade Federal de Santa Maria. Graduada em direito e jornalismo pela UFSM. E-mail: mariliadb@yahoo.com.br. 
Resumo: A relação estabelecida entre pobreza e criminalidade é uma das leituras mais comuns no tema da violência no Brasil. Na esfera da infância e da juventude, essa concepção está ainda mais enraizada, pois o adolescente pobre é compreendido sob a ótica tutelar: de vítima da sociedade a vitimizador. Este trabalho busca problematizar essa perspectiva diante de duas rupturas de paradigma: a que funda a criminologia crítica e trata o tema segundo uma leitura macroestrutural da criminalização da pobreza; e a que funda a doutrina da proteção integral na área da infância e juventude, rompendo com a perspectiva tutelar. A partir desse arcabouço teórico, e a partir do método dialético, a análise de conteúdo realizada em acórdãos do Superior Tribunal de Justiça permite verificar que o sistema da infância e juventude mantém brechas menoristas e antidemocráticas, fazendo com que os adolescentes sejam compreendidos sob a chave da periculosidade, disfarçada de vulnerabilidade.

Palavras-chave: Ato infracional. Medidas socioeducativas. Criminologia crítica. Vulnerabilidade. Periculosidade.

Abstract: The relationship between poverty and crime is one of the most common readings on the subject of violence in Brazil. In the realm of childhood and youth, this concept is even more entrenched, because poor teenagers are seen from a tutelary perspective: from victim of society to victimizer. This work investigates this perspective based on two paradigm shifts: one based on critical criminology, which deals with the theme according to a macro-structural reading of the criminalization of poverty; and the other based on the doctrine of integral protection in the area of childhood and youth, breaking away from the tutelary perspective. Within this theoretical framework, and based on a dialectical method, the content analysis carried out on judicial decisions of the Superior Court of Justice enables us to see that the system of childhood and youth has minority and anti-democratic gaps, such that teenagers are understood from a perspective of dangerousness, disguised as vulnerability. 
Keywords: Youth crime. Socio-educational measures. Critical criminology. Vulnerability. Dangerousness.

Resumen: La relación establecida entre pobreza y criminalidad es una de las lecturas más comunes en el tema de la violencia en Brasil. En la esfera de la infancia y de la juventud esa concepción está aún más arraigada, pues el adolescente pobre es comprendido desde el punto de vista tutelar: de víctima de la sociedad a victimizador. Este trabajo intenta problematizar esa perspectiva frente a dos rupturas de paradigma: la que funda la criminología crítica y trata el tema según una lectura macro estructural de la criminalización de la pobreza; y la que funda la doctrina de la protección integral en el área de la infancia y juventud, rompiendo con la perspectiva tutelar. A partir de ese marco teórico, y a partir del método dialéctico, el análisis de contenido realizado en sentencias del Superior Tribunal de Justicia permite verificar que el sistema de la infancia y la juventud preserva brechas menoristas y antidemocráticas, haciendo que los adolescentes sean comprendidos en una clave de peligrosidad, disfrazada de vulnerabilidad.

Palabras clave: Acto infraccional. Medidas socioeducativas. Criminología crítica. Vulnerabilidad. Peligrosidad.

\section{INTRODUÇÃO}

relação direta estabelecida discursivamente entre pobreza e
criminalidade é uma das leituras mais comuns no tema da violência
no Brasil. Na esfera da infância e juventude essa concepção está ainda mais enraizada, pois o adolescente pobre é compreendido sob a ótica tutelar: de vítima da sociedade a vitimizador; de criança em perigo a adolescente perigoso. Este trabalho busca problematizar essa perspectiva diante de duas rupturas de paradigma: a que funda a criminologia crítica e trata o tema segundo uma leitura macroestrutural da criminalização da pobreza; e a que funda a doutrina da proteção integral na área da infância e juventude, rompendo com a perspectiva tutelar em prol do reconhecimento de crianças e adolescentes como sujeitos de direitos. 
O momento atual é de expansão do sistema penal na maior parte dos países, de maneira que diferentes emergências vêm se sobrepondo às questões sociais na ótica dos governos. Na esteira de outros países, como os Estados Unidos, o Brasil vem inflando seu lado repressor nos últimos vinte anos, tendo multiplicado por quatro o número de adolescentes internados nos últimos quinze anos e por três o número de adultos encarcerados nos últimos dez anos. A utilização do braço repressor do Estado vem simbolizada na quantidade de privações de liberdade de adolescentes, bem como nas estatísticas de assassinatos de que foram vítimas. Daí que tentar compreender, por meio do método dialético os mecanismos discursivos que movem a adoção de posturas punitivistas baseadas em preconceitos sociais que alimentam a seletividade do sistema penal, parece ser um importante caminho na sua desconstrução. Parte-se, assim, da hipótese de que, por mais avançada que seja a legislação em matéria de direito da criança e do adolescente, os resquícios menoristas vêm se sobrepondo com um viés inquisitorial e tutelar.

O trabalho se divide em duas partes. Na primeira, busca-se trabalhar, em uma perspectiva histórica, a construção social do paradigma menorista, com o intuito de, na segunda parte, problematizar a ideia de vulnerabilidade que costuma ser atribuída nos dias atuais a algumas crianças e adolescentes. Na segunda parte, apresenta-se o resultado da análise de conteúdo de 26 acórdãos do Superior Tribunal de Justiça sobre a relação entre ato infracional e vulnerabilidade. $O$ objetivo é o de problematizar o uso dessa categoria na decisão a respeito da medida socioeducativa adotada pelos julgadores. Busca-se inverter a lógica desse conceito: da vulnerabilidade como dado ontológico relacionado à condição pessoal e social do adolescente à vulnerabilidade em relação ao sistema penal.

\section{MARGINALIZADOS E VULNERÁVEIS: O FOCO DO SISTEMA DE CONTROLE DA JUVENTUDE NO BRASIL}

Historicamente, a criança e o adolescente passaram a ser objeto de preocupação do Estado a partir de uma leitura que pode ser traduzida no binômio abandonoinfração. De fato, é o menor como problema de ordem pública o objeto das 
políticas elaboradas a partir de fins do século XIX no Brasil. Para compreender essa relação e sua ligação com a ideia de marginalização social, vulnerabilidade e ato infracional, este tópico primeiramente busca apresentar a emergência e a consolidação do chamado paradigma menorista, o qual ainda prepondera em muitas das instituições brasileiras (1.1); para em seguida estabelecer algumas das principais distinções entre o paradigma menorista e o paradigma da proteção integral, instituído no Brasil a partir de 1988 muito mais como vir-a-ser do que como uma realidade (1.2).

\section{DE VÍTIMAS A BANDIDOS: A PERCEPÇÃO SOCIAL DA INFÂNCIA E JUVENTUDE NO BRASIL}

A compreensão que se tem hoje da infância e da juventude é o resultado de uma longa construção social, sabendo-se que até o século XVII sequer o sentimento de infância estava presente na Europa ${ }^{2}$. A relação da infância à incapacidade e à necessidade de tutela surge a partir de final do século XIX e início do século XX. No Brasil, a filosofia positivista, que sustentou ideologicamente a Proclamação da República, também foi responsável por uma maior preocupação assistencial dirigida a vários grupos sociais, dentre eles os jovens. A moral do trabalho e a necessidade de disciplinamento vêm acompanhadas nesse período de um grande internamento de crianças, jovens e adultos, todos aqueles que não estivessem de acordo com os padrões da sociedade da época³

Nesse período, o interesse do Estado pelos menores de idade se amplia e faz com que essa designação se estenda de uma mera categoria jurídica a um caráter eminentemente social e político ${ }^{4}$. É nesse contexto que nasce o paradigma menorista e a categoria menor. agora não mais um adjetivo comparativo, mas um substantivo de significado equívoco, e paulatinamente enraizado na sociedade brasileira.

2 ARIÉS, Philippe. História social da criança e da família. Tradução de Dora Flaksman. 2. ed. LTC, 1981.

3 LONGO, Isis S. Da legislação menorista ao ECA: mudanças e permanências nos discursos e imaginário sobre a conduta infanto-juvenil. Anais do Seminário Educação 2009. 17. ed. Políticas educacionais: cenários e projetos sociais. Disponível em: http://www.ie.ufmt.br/ semiedu2009/gts/gt8/ComunicacaoOral/ISIS\%20 SOUSA\%20LONGO.pdf. Acesso em: 29 ago. 2012.

4 RIZZINI, Irene; RIZZINI, Irma. A institucionalização de crianças no Brasil: Percurso histórico e desafios do presente. Rio de Janeiro: PUC-Rio; São Paulo: Loyola, 2004. 
O Brasil é, nesse momento, influenciado também pelo que ocorre em outras partes do mundo. Os tribunais específicos de menores começam a surgir no início do século XX nos Estados Unidos, e também em vários países europeus e latinoamericanos. É o período das reformas, embasadas, sobretudo, na criminologia positivista, que tem em sua base a etiologia do crime e o determinismo. Em termos ideológicos, a criminologia positivista dá origem à ideia da defesa social e então, a partir desse momento, o agir sobre a chamada infância "desvalida" passou a ser compreendido como uma forma de evitar a transformação - certa - da criança abandonada na criança delinquente.

Esse determinismo teórico legitimava o deslocamento da reprovação de condutas cometidas pelo sujeito no passado - base da legitimidade da aplicação de sanções no direito penal clássico - "a uma reprovação - com base em um diagnóstico pseudocientífico - ao que no futuro possa chegar a fazer a criança ou o adolescente" 5 . A previsão do futuro é, assim, realizada em conjunto: "através de ferramentas como os exames de discernimento se busca detectar o grau de 'enfermidade' de que padece o sujeito e com base nisso o juiz - que melhor atuaria aqui como um médico - receita o remédio adequado a cada situação" ${ }^{6}$.

O Código de Menores, publicado em 1927, para compilar toda a legislação existente até então sobre a assistência aos menores, trazia um artigo para determinar o papel que deveria exercer o médico psiquiatra no juízo de menores, demonstrando "a inter-relação entre as práticas médicas e jurídicas na definição do menor como um objeto institucional"7. O discurso médico, fundamental na ideia do tratamento e da cura do delinquente, é atravessado pelos saberes psicológico e antropológico, correntes essas que ergueram, segundo García Mendez e Costa, "a obra mais gigantesca de negação e mistificação dos profundos conflitos estruturais, que as sociedades latino-americanas atravessam" ${ }^{\text {. }}$

5 CORTÉS MORALES, Julio. A 100 años de la creación del primer Tribunal de Menores y 10 años de la Convención Internacional de los Derechos del Niño: el desafío pendiente. In: UNICEF. Justicia y derechos del niño, n. 9. Santiago, Chile: 2007. p. 143-158. p. 146.

6 CORTÉS MORALES, Julio. A 100 años de la creación del primer Tribunal de Menores y 10 años de la Convención Internacional de los Derechos del Niño. p. 146.

7 LONGO, Isis S. Da legislação menorista ao ECA.

8 GARCÍA MENDEZ, Emilio; COSTA, Antonio Caros Gomes. Das necessidades aos direitos. São PauIo: Malheiros, 1994. p. 29. 
No contexto dessa matriz teórica, empregada claramente na prática da institucionalização de crianças, acaba se legitimando a ideia de que a pobreza gera criminalidade e um novo tipo de infância e adolescência é então criado: a menoridade. "A categoria 'menor' é construída então para designar a criança objeto da Justiça e da Assistência, tornando-se o alvo das políticas de internação" ${ }^{\prime 9}$.

É evidente na história uma diferenciação essencial para compreender o status da infância nesse período: o foco desse sistema assistencial, assim como o do repressivo sempre foi voltado para os mesmos grupos sociais, aqueles das classes sociais baixas e não brancas. Como observa Rizzini, na análise da literatura histórica, em diferentes fontes consultadas a respeito da criança, o que mais aparece é a preocupação com os estratos empobrecidos da população, seja em razão de sua orfandade, abandono ou exposição, seja em função da libertinagem, vício ou delinquência ${ }^{10}$.

O Código de Menores era, portanto, destinado especificamente a um grupo especial designado pelas expressões: crianças de primeira idade (art. $2^{\circ}$ ), infantes expostos (art. 14), menores abandonados (art. 26), menores vadios (art. 28), menores mendigos (art. 29), menores libertinos (art. 30), menores delinquentes (art. 68), capoeiras (art. 78) $)^{11}$.

Para García Méndez e Costa, a indistinção entre menores abandonados e delinquentes se converteu na profecia que se autorrealiza, e cita a fala de Arenaza, juiz de menores e teórico argentino da época, para explicar: "Dá-se que, em determinados casos, simula-se ou acusa-se a criança de uma contravenção para que a ação protetora do Estado possa tornar-se um benefício"12. Assim, se a criança não fosse nem vítima imediata, nem ofensora, não teria como o Estado agir para protegê-la (e principalmente controlá-la). A rigor, se para as crianças continuasse a ser utilizado o paradigma do direito penal liberal, não haveria como o Estado intervir. A praticidade de se anular as garantias jurídicas se dá no

9 RIZZINI, Irene; RIZZINI, Irma. A institucionalização de crianças no Brasil. p. 68.

10 RIZZINI, Irene. O século perdido: Raízes históricas das políticas públicas para a infância no Brasil. 2 ed. rev. São Paulo: Cortez, 2008.

11 BRASIL. Decreto n 17.943-A de 12 de outubro de 1927. Consolida as leis de assistência e protecção a menores. Disponível em: http://www.planalto.gov.br/ccivil_03/decreto/1910-1929/D17943Aimpressao. htm. Acesso em: 24 ago. 2012.

12 GARCÍA MENDEZ, Emilio; COSTA, Antonio Caros Gomes. Das necessidades aos direitos. p. 48. 
sentido de garantir a eficácia das tarefas de "proteção-repressão"13.

A questão das medidas por tempo indeterminado, impostas por um juiz-pai, sem as figuras da acusação e da defesa, foi um dos principais pontos sustentados nas origens ideológicas do reformismo emergente no início do século XX. Para a maior parte dos entendidos em assunto de menores na época, a medida por tempo determinado seria contraproducente, pois significaria uma proteção temporária, no lugar de uma proteção permanente ${ }^{14}$. Transmudando-se, então, a pena em proteção, permitia-se que a resposta ao ato criminoso praticado por criança ou adolescente fosse encarada como um bem: o Estado intervém no sentido de protegê-lo, e não de puni-lo, ainda que a principal resposta fosse a privação da liberdade por tempo indeterminado.

Por mais que, na década de 1960, a instituição da Fundação Nacional de Bem-Estar do Menor (FUNABEM) pretendesse romper com a cultura da institucionalização e priorizar programas de integração comunitária, essa ruptura não ocorreu. Como notam Rizzini e Rizzini, "[...] o grande modelo difundido no período foi o do internato de menores, ou os 'internatos-prisão' [...]", chegandose a internar, apenas entre 1967 e 1972, 53 mil crianças $^{15}$.

O discurso da desinstitucionalização não se ajustava à doutrina de segurança nacional, e justamente por isso não é uma surpresa que a eficácia da FUNABEM tenha sido invertida.

O chamado problema do menor foi inserido nos aspectos psicossociais da política de segurança. O menor foi pensado como um dos objetivos nacionais permanentes, isto é, aqueles que se realizam em longo processo histórico através da definição dos elementos fundamentais da nacionalidade como a terra, o homem e as instituições ${ }^{16}$.

O menor desassistido, categoria utilizada à época da instituição e do desenvolvimento da FUNABEM, era conceituado como "todo menor que, atingido pelo processo de marginalização, se constitui em 'Menor-Problema Social'"17. Duas 13 GARCÍA MENDEZ, Emilio; COSTA, Antonio Caros Gomes. Das necessidades aos direitos.

14 GARCÍA MENDEZ, Emilio; COSTA, Antonio Caros Gomes. Das necessidades aos direitos.

15 RIZZINI, Irene; RIZZINI, Irma. A institucionalização de crianças no Brasil. p. 37.

16 PASSETTI, Edson. O menor no Brasil republicano. In: DEL PRIORE, Mary (Org.). História da criança no Brasil. São Paulo: Contexto, 1991. p. 146-175. p. 151.

17 BRASIL. Ministério da Previdência e Assistência Social. Fundação Nacional do Bem-Estar do Menor. 0 
categorias do menor desassistido eram ressaltadas: o menor carenciado, "aquele que, em virtude do não atendimento de suas necessidades básicas e da ausência ou incapacidade dos pais ou responsáveis, se encontra em situação de abandono total ou de fato, ou está sendo vítima de exploração" e o menor de conduta antissocial, "aquele que infringe as normas éticas e jurídicas da sociedade"18. A origem de ambas as categorias de menores está na marginalização social, processo entendido como "[...] uma situação de baixa renda, de pouca participação no consumo de bens materiais e culturais, de incapacidade de trazer a si os serviços de habitação, saúde, educação e lazer"19.

Isso significa que o menor de conduta antissocial é originado na pobreza, de maneira que o PNBEM e a FUNABEM tinham já, em seu discurso declarado, a identificação de seu foco como sendo apenas o daquele grupo social: menor é o menor de 18 anos em situação de marginalidade social e, portanto, tanto o aspecto assistencial como o correcional - muitas vezes indistintos - estava voltado para eles. Se, por um lado, a insistência no debate sobre o aspecto socioeconômico para identificar a origem do "menor-problema social" pode ser vista como um aparente avanço, por outro lado, as pessoas são culpabilizadas pela sua situação de marginalização.

Seguindo a lógica da PNBEM, em 1979, ainda durante a ditadura militar, surge o novo código de menores. Lá, seus primeiros artigos se dedicam a apresentar a finalidade dessa lei: assistência, proteção e vigilância; e o seu objeto: menores até dezoito anos de idade em situação irregular e os menores entre dezoito e vinte e um anos nos casos dispostos em lei. Trata-se do aprofundamento da chamada Doutrina da Situação Irregular. Assim, todas aquelas qualificações presentes no Código de 1927 para designar os menores que seriam o objeto de proteção, vigilância e assistência aqui são englobados dentro da terminologia da situação irregular.

Para Custódio, a continuidade da identificação menorista das crianças e dos adolescentes pobres como "menores em situação de risco" ressignificava a realidade,

"menor-problema social” no Brasil e a ação da FUNABEM. Rio de Janeiro: MPAS, 1976. p. 21.

18 BRASIL. Ministério da Previdência e Assistência Social. Fundação Nacional do Bem-Estar do Menor. p. 21.

19 BRASIL. Ministério da Previdência e Assistência Social. Fundação Nacional do Bem-Estar do Menor. p. 14. 
na medida em que acabava por responsabilizá-los individualmente por sua condição de "irregularidade". "Era a construção de um mundo paralelo, onde a irregularidade era imaginada com base em preconceitos e estereótipos e depois restava aos agentes do Estado enquadrar o público perfeito à caracterização da barbárie"20.

Quanto à previsão legal no Código de Menores sobre a responsabilização dos autores de infrações penais, observa-se que, apesar de a internação ser medida subsidiária às demais, o artigo 41 deixa claro que não há limite máximo de tempo para a aplicação dessa medida, dependendo de que "a autoridade judiciária, em despacho fundamentado, determine o desligamento, podendo, conformea natureza do caso, requisitar parecer técnico do serviço competente e ouvir o Ministério Público" ${ }^{21}$. A verificação sobre a manutenção ou a permanência da medida deveria ser realizada periodicamente, com intervalos máximos de dois anos $\left(\$ 2^{\circ}\right)$.

Daí que se os adultos autores de infrações penais tinham em seu favor as garantias penais e processuais penais, penas sempre limitadas no tempo, com prazo a depender da gravidade da conduta, os adolescentes não dispunham de nada disso, ficando completamente à mercê do arbítrio judicial.

\section{A DOUTRINA DA PROTEÇÃO INTEGRAL: UM VIR-A-SER}

A abertura política no Brasil e o avanço na legislação internacional a respeito da criança e do adolescente foram a combinação perfeita para a elaboração de uma lei histórica no trato desse contingente. Foram vários os setores que intervieram nesse tema no final da década de 1970 e no início da década de 1980. A influência da Igreja Católica esteve presente com a chamada Pastoral do Menor. O movimento de defesa das crianças congregou desde aqueles vinculados a FEBEMs, administradores, técnicos e outros trabalhadores, até intelectuais, pais de crianças internadas, líderes comunitários, defensores de direitos humanos e outros cidadãos.

20 CUSTÓDIO, André Viana. Teoria da proteção integral: pressuposto para compreensão do direito da criança e do adolescente. Revista do Direito, v. 29, p. 22-43, Santa Cruz do Sul, 2008. p. 25.

21 BRASIL. Lei $n^{\circ}$ 6.697, de 10 de outubro de 1979. Institui o Código de Menores. Disponível em: http://www.planalto.gov.br/ccivil_03/leis/1970-1979/L6697impressao.htm. Acesso em: 25 ago. 2012. 
Ao longo da década de 1980, uma das características do trabalho da sociedade civil para com as crianças foi a utilização da Educação Social de Rua, buscando interagir com as crianças em situação de rua e propiciar a autonomia desse público, por meio de práticas libertárias. Os agora chamados meninos e meninas de rua não eram mais entendidos como incapazes, vítimas de suas famílias desajustadas ou de um sistema econômico injusto e, portanto, passivas destinatárias de políticas assistencialistas que escondem o controle e a repressão, mas sim como agentes de suas próprias vidas, promotores de uma nova sociedade justa, fraternal e participativa ${ }^{22}$. A propagação dessas ações levou o seu desenvolvimento para fora de São Paulo, onde nasceu e, em 1985, foi fundado o Movimento Nacional de Meninos e Meninas de Rua (MNMMR).

Esse é o significado da nova concepção da criança e do adolescente como sujeitos de direitos, como sujeitos políticos e, portanto, como cidadãos. Para Santos, esse momento histórico simboliza a mudança de uma compreensão jurídicopolítica da criança relacionada ao filantropismo leigo e religioso para aquela compreensão associada à ação de emancipação do cidadão no século $X X^{23}$.

O resultado de toda essa mobilização está no artigo 227 da Constituição Federal promulgada em 1988:

Art. 227. É dever da família, da sociedade e do Estado assegurar à criança e ao adolescente, com absoluta prioridade, o direito à vida, à saúde, à alimentação, à educação, ao lazer, à profissionalização, à cultura, à dignidade, ao respeito, à liberdade e à convivência familiar e comunitária, além de colocá-los a salvo de toda forma de negligência, discriminação, exploração, violência, crueldade e opressão ${ }^{24}$.

Esse texto traz claramente a adoção da doutrina da proteção integral e o respeito aos princípios da Convenção Internacional dos Direitos da Criança, com um detalhe: ela ainda não havia sido assinada. Isso ocorre apenas em 1989, mas a antecipação havia sido possível graças à mobilização dos grupos sociais organizados interessados na superação da doutrina da situação irregular.

22 OLIVEIRA, Walter F. de. Educação social de rua: bases históricas, políticas e pedagógicas. História, Ciências, Saúde, Manguinhos, Rio de Janeiro, v. 14, n.1, p.135-158, jan.-mar. 2007.

23 SANTOS, Benedito Rodrigues dos. 18 anos de ECA: a inclusão de crianças e adolescentes no estado de direitos brasileiro, Inclusão social, Brasília, v. 2, n. 2, p. 152-154, abr.-set. 2007.

24 BRASIL. Constituição (1988). Disponível em: <http://www.planalto.gov.br/ccivil_03/Constituicao/Constituicao.htm>. Acesso em: 22 ago. 2014. 
O Estatuto da Criança e do Adolescente foi uma conquista desses mesmos grupos que participaram na implementação de uma legislação para todas as crianças e não só para aquelas marginalizadas. Além de todos os direitos e garantias individuais dos adultos, as crianças passaram a dispor daqueles relacionados à sua condição peculiar de ser humano em desenvolvimento.

Quanto ao ato infracional, as medidas socioeducativas foram elaboradas no intuito de manter a separação entre adultos e adolescentes no sistema prisional e, ao mesmo tempo, tornar excepcional a privação de liberdade. As medidas são condicionadas a uma condenação judicial, por meio de um processo em que imperam todas as garantias processuais, sobretudo o direito de defesa. Tudo o que implicar redução de direitos não pode ser encarado como um bem para a criança e o adolescente. Sendo assim, não mais se admite a privação da liberdade para a proteção do adolescente. Para proteger foram criadas as medidas protetivas que não contemplam a privação da liberdade.

Entretanto, apesar de todas as garantias, em especial o direito à ampla defesa, diferentes estudos vêm mostrando que, se na esfera criminal adulta ainda persiste a mentalidade inquisitorial, na esfera da infância e da juventude ela chega a ser caricatural, como bem representado no documentário de Maria Augusta Ramos, "Juízo". No âmbito da academia, um exemplo é o estudo etnográfico da antropóloga Paula Miraglia, realizado nas audiências da Vara de Infância e Juventude do Brás, em São Paulo, no qual demonstra que acusado e defensor são totais coadjuvantes, figurando à sombra do protagonista, que fala, interpreta, aconselha e julga - legal e moralmente: o juiz da infância e da juventude ${ }^{25}$.

As posições existentes, seja na representação da criança e do adolescente, seja na questão das políticas públicas relacionadas a essas pessoas, podem ser resumidamente três: repressivos - não ultrapassaram a situação irregular; protetivos e democráticos, que defendem a responsabilização dos adolescentes e primam pelas políticas de universalização das políticas sociais, mais a que programas assistencialistas pontuais, sempre atravessada pela participação política da sociedade, mas também dos próprios membros desse grupo social; e 25 MIRAGLIA, Paula. Aprendendo a lição: uma etnografia das Varas Especiais da Infância e da Juventude. Novos

Estudos, n. 72, jul. 2005. p. 79-98. 
uma posição, que assume teoricamente os postulados da proteção integral, mas não arca com todas as suas consequências, especialmente a de abrir mão do conceito de vulnerabilidade e assumir a responsabilidade penal que obrigue as autoridades a abrir mão da discricionariedade para lidar com a infância ${ }^{26}$. Isso implica a redução da busca pelo diagnóstico discricionário a respeito da existência e das características da disfunção individual do adolescente autor de ato infracional ou social. García Méndez denomina essa posição de "paradigma da ambiguidade"27.

Tal paradigma parece ser predominante tanto na esfera judicial quanto na executiva e mesmo na legislativa. Estudo recente realizado nos projetos de lei elaborados por deputados federais entre 2009 e 2012 concluiu que se mantém naquela esfera a relação direta entre pobreza e criminalidade, e entre trabalho e regeneração do indivíduo ${ }^{28}$. Em estudo sobre os documentos destinados à prevenção da criminalidade dos jovens no âmbito da Secretaria Nacional de Segurança Pública do Ministério da Justiça nos anos 2000, Kulaitis conclui que tais documentos estabelecem uma relação direta entre juventude pobre e criminalidade, trabalhando com a ideia de prevenção da violência diretamente focada nas periferias ${ }^{29}$.

Talvez seja no Judiciário, porém, que se encontrem as evidências mais palpáveis a respeito da adoção do paradigma da ambiguidade. É a respeito do discurso do STJ, uma das mais altas cortes do país que se buscará, no próximo tópico, compreender a postura adotada diante da situação do adolescente autor de ato infracional, delimitando a análise à questão da vulnerabilidade.

\section{O MENORISMO ENRUSTIDO NOS ACÓRDÃOS DO STJ: SOBRE O CONCEITO DE VULNERABILIDADE}

A vulnerabilidade não existe senão em relação a algo. Esse é um dos pontos de que parte Uriarte para discutir o conceito de vulnerabilidade tal qual usado na área da infância e da juventude para decidir sobre as mais diversas questões ${ }^{30}$.

26 GARCÍA MÉNDEZ, Emilio. Infancia, ley y democracia: una cuestión de justicia. In: UNICEF. Justicia y derechos del niño, n. 9. Santiago, Chile: 2007. p. 27-47.

27 GARCÍA MÉNDEZ, Emilio. Infancia, ley y democracia.

28 BUDÓ, Marília De Nardin. De vítimas a bandidos: o caráter equívoco do tratamento da infância e da adolescência nos projetos lei propostos na Câmara dos Deputados. In: Anais do IV Seminário Internacional de Sociologia e Política. Curitiba: UFPR, 2012.

29 KULAITIS, Letícia Figueira Moutinho. Entre a vitimização e a criminalização: a juventude como foco das políticas de segurança pública. In: Anais do IV Seminário Internacional de Sociologia e Política. Curitiba: UFPR, 2012.

30 URIARTE, Carlos E. Vulnerabilidad, privación de libertad de jóvenes y derechos humanos. 
Neste tópico do artigo busca-se estabelecer uma análise crítica desse conceito, a partir da criminologia crítica, partindo de sua utilização quando relacionada ao tema do ato infracional nas decisões do Superior Tribunal de Justiça (STJ).

O primeiro subitem traz os resultados da análise de conteúdo de 26 acórdãos, resultantes da pesquisa na jurisprudência daquele tribunal a partir do termo de busca "ato infracional e vulnerabilidade". São todas decisões publicadas no período de 21 de outubro de 2010 a 16 de outubro de 2012. Trata-se de concessões ou denegações de ordem de Habeas Corpus, ação fundamentada no artigo 50, LXVIII da Constituição Federal de 1988, utilizada em situações nas quais o paciente entende estar passando por um constrangimento ilegal em sua liberdade de ir e vir. Os casos analisados tratavam, sobretudo, de situações nas quais a internação provisória havia sido decretada pelo juízo de primeiro e segundo graus, ou quando o paciente havia sido condenado ao cumprimento de medidas socioeducativas de semiliberdade ou de internação e a decisão havia sido mantida no Tribunal de Justiça do estado de origem.

O objetivo da pesquisa é o de identificar o conceito de vulnerabilidade, da maneira como atribuída aos acusados de serem autores de atos infracionais nas decisões do STJ, bem como analisar qual uso é feito desse termo no momento da decisão. As decisões foram catalogadas conforme seu pertencimento a uma das duas categorias, ligadas ao uso que se faz da vulnerabilidade, entendida como condição social do adolescente que indica: a) a necessidade de intervenção do Estado na forma de medidas de privação da liberdade para a sua correção e ressocialização; b) a necessidade de aplicação de medida protetiva e não socioeducativa. O segundo subitem realiza a análise crítica desse conceito a partir da criminologia crítica, tendo como principais referências as obras de Alessandro Baratta, Eugenio Raúl Zaffaroni e Carlos Uriarte.

\section{VULNERABILIDADE EM RELAÇÃO A ...?}

Uma questão intrigante relacionada já ao conteúdo das decisões é o uso corriqueiro dos termos Estatuto Menorista, Juízo menorista, magistrado ou juiz 
menorista, sentença menorista, para designar, respectivamente, o Estatuto da Criança e do Adolescente, a Justiça da Infância e da Juventude, o juiz da vara da infância e da juventude e a decisão judicial do juiz da vara da infância e da juventude. Esses termos, por si sós, permitem já um primeiro diagnóstico da maneira como os adolescentes são compreendidos nesse tribunal. A revolução na linguagem de que falam todos os autores ligados ao direito da criança e do adolescente não se operou em uma das mais altas cortes do país, deixando de compreender o arcabouço de significados que está por detrás dos termos menor e seus derivados. Da mesma maneira, a expressão menor infrator é de uso corriqueiro.

Considerando a origem e a história dessas expressões, sabe-se que menores são aqueles adolescentes e crianças compreendidos como objetos de tutela em vez de sujeitos de direitos, dado que deve o Estado evitar que se transformem em uma ameaça à sociedade. Esse uso não é fortuito, tendo sido aplicado historicamente às crianças e aos jovens tomados como problemas: "Não problemas quaisquer, mas aqueles derivados da pobreza ou de aspectos étnico-raciais devidamente estigmatizados por intermédio de processos e dinâmicas criminalizadoras"31. A manutenção desse termo no STJ é significativa e demonstra a adoção da postura do juiz de menores, aquele detentor de numerosos poderes e que, sobretudo, sabe o que é para o "bem" dos adolescentes.

Quanto à palavra vulnerabilidade, objeto desta pesquisa, nota-se que ela foi empregada sempre em conjunto com a análise das condições pessoais e sociais do adolescente para determinar a medida socioeducativa ou protetiva mais adequada nas seguintes situações: 1) condição econômica desfavorável; 2) família desestruturada; 3) perda do pai ou da mãe; 4) influência negativa de membros da família; 5) prática de outros atos infracionais; 6) gravidez; 7) uso de entorpecentes; 8) dificuldade de cumprir normas e regras 9) identidade com a vida nas ruas; 10 ) abandono da escola; 11) más companhias; 12) pai e/ou mãe presos. Essas situações costumam ser apresentadas em conjunto, dependendo do caso do adolescente em questão e do que se está buscando fundamentar ao utilizar o termo vulnerabilidade.

31 MORAES, Pedro Rodolfo Bodê de; PESCAROLO, Joyce Kelly. Quem tem medo dos jovens? Disponível em: http://www.naoviolencia.org.br/pdf/quemtemedodosjovens.pdf. Acesso em: 20 ago. 2012. 
De qualquer maneira, a vulnerabilidade é apresentada como um dado pertencente ao indivíduo que está sendo julgado, sem grandes explicações ou contextualizações: trata-se de uma perspectiva que entende que, ontologicamente, as pessoas marginalizadas são vulneráveis. Mas em relação a que essas pessoas são vulneráveis, é uma questão não respondida diretamente.

Em algumas situações, lê-se que o adolescente está em risco por conta dessa vulnerabilidade. Risco, por exemplo, de ser vítima de alguma agressão ou mesmo de passar fome ou necessidades. Em outras situações, especialmente quando ligada ao uso de drogas, à prática de outros atos infracionais e às más companhias, a vulnerabilidade parece ser entendida como propensão ao crime. Trata-se de uma estreita relação com o conceito de periculosidade: ao analisar a vida pregressa do indivíduo, faz-se uma projeção do que será o seu futuro. Confirma-se aí a passagem linearmente compreendida do menor em perigo, em decorrência de suas condições sociais, ao menor perigoso: de vítima da sociedade desigual e de pais irresponsáveis a algoz dessa mesma sociedade.

Em todos os casos, porém, o uso da vulnerabilidade está profundamente relacionado com a categoria da situação irregular, típica do menorismo. Entendese que o Estado deve agir sempre que um "menor" está em situação irregular, especialmente em situação de perigo moral, com desvio de conduta ou autor de infração penal. Assim, em determinadas situações, ainda que o fato não seja considerado grave e o adolescente não esteja reiterando em sua conduta, aplicamse medidas mais graves, como a semiliberdade e a internação pelo fato de que o adolescente não tem condições de se reintegrar socialmente, por ser vulnerável.

A ideia de vulnerabilidade ao mundo do crime em decorrência da marginalização, que se denota da maior parte dos entendimentos, implica sempre uma relação determinista entre pobreza e criminalidade, aquela mesma, de herança positivista, sobre a qual se falou no tópico anterior. Ao se partir das condições pessoais e sociais do adolescente para definir que medida deve ser aplicada, julga-se por meio do direito penal de autor, e não do direito penal do fato. Como observa Uriarte, "qualquer uso do termo proteção da infância, por fora de seus direitos é eufemístico. Proteger a criança vulnerando seus direitos 
é uma contradição nos termos"32.

Quanto às situações para as quais o termo vulnerabilidade foi instrumentalizado, dois grupos de resultados puderam ser encontrados nos 26 acórdãos analisados. No primeiro grupo - de 24 acórdãos - encontram-se os entendimentos de que a situação de vulnerabilidade indica a necessidade de maior intervenção do Estado para corrigir o adolescente, sendo as medidas mais graves - a semiliberdade e a internação - consideradas as mais adequadas para a sua "proteção". No segundo grupo, no qual constam dois acórdãos, entende-se a vulnerabilidade como situação que enseja a adoção de medidas protetivas e não socioeducativas.

No primeiro grupo, apesar de todos os entendimentos se voltarem à vulnerabilidade como ensejadora de medidas de privação da liberdade, os conceitos e os fundamentos se diferenciam. Em primeiro lugar, tem-se o entendimento de que a vulnerabilidade implica a necessidade de medida de semiliberdade, buscando reinserir o adolescente no convívio social. Em um caso de furto de $R \$ 70,00$, a ministra relatora entendeu que, mesmo diante do baixo valor do produto do furto, a medida socioeducativa de semiliberdade deve perdurar, pois ela "tem por objetivo a reinserção do adolescente em situação de risco"33. Por isso, entendeu que a adoção da medida de semiliberdade foi

[...] exaustivamente fundamentada, tendo o magistrado relatado as condições pessoais e sociais do paciente, ressaltando a condição familiar desfavorável do adolescente, com a perda precoce do genitor e a influência negativa de membros da família, com menção, inclusive, à prática de outros atos infracionais, demonstrando, com isso, tanto a situação de vulnerabilidade do paciente e a necessidade da aplicação das medidas de semiliberdade, inexistindo, assim, o alegado constrangimento ilegal ${ }^{34}$.

Nesse caso, semelhante a vários outros julgados pela mesma ministra, entendese a vulnerabilidade em relação à situação de marginalização social e família desestruturada, chegando à conclusão de que há a necessidade de se interferir 32 URIARTE, Carlos E. Vulnerabilidad, privación de libertad de jóvenes y derechos humanos. p. 25.

33 BRASIL. Superior Tribunal de Justiça. Habeas Corpus n²38756 - Distrito Federal. Relator: Min. Marco Aurélio Bellizze. Acórdão de 28 de agosto de 2012. Disponível em: https://ww2.stj.jus.br/revistaeletronica/Abre_Documento.asp?sLink=ATC\&sSeq=23808048\&sReg=201200713402\&sData=20120920\&sTipo=5\&formato=PDF. Acesso em: 01 nov. 2012.

34 BRASIL. Superior Tribunal de Justiça. Habeas Corpus n²38756 - Distrito Federal. Grifou-se. 
na formação do adolescente para que se reverta essa situação. Em outra decisão aparece compreensão semelhante:

Ademais, além de considerar a reiteração de atos infracionais, o Tribunal de origem ressaltou as condições pessoais do paciente (o adolescente encontra-se em completo estado de vulnerabilidade, apesar de inserido em seu núcleo familiar, uma vez que "... a partir dos 14 anos de idade começou a ser infrequente às aulas, se aproximou das drogas e de pessoas com conduta duvidosa, apesar das orientações familiares (...) deixou de estudar no ano passado (...) seu meio social é caracterizado por vulnerabilidade...") para o estabelecimento da medida socioeducativa de internação $0^{35}$.

Mais uma vez, não se define claramente em relação a que se depreende a caracterização de vulnerabilidade, sempre julgando a história de vida do autor para determinar como responder pela prática de seu ato. Na ementa a seguir, percebe-se que a situação de vulnerabilidade é um dos principais motivos ensejadores da adoção da segunda mais gravosa medida socioeducativa:

\section{HABEAS CORPUS. ECA. ATO INFRACIONAL EQUIPARADO A TRÁFICO DE ENTORPECENTES. MEDIDA SOCIOEDUCATIVA DE SEMILIBERDADE. FUNDAMENTAÇÃO IDÔNEA. ORDEM DENEGADA.}

1. Mostra-se devidamente fundamentada a imposição da medida socioeducativa de semiliberdade, com base nas peculiaridades do caso concreto, notadamente a situação de vulnerabilidade do paciente, o qual se encontra envolvido com o tráfico de drogas e afastado dos estudos e do trabalho.

\section{Agravo regimental a que se nega provimento ${ }^{36}$.}

Em segundo lugar, aparece o entendimento de que nessas situações revelase a necessidade de um acompanhamento por parte do Estado, para controlar o adolescente e também garantir que ele não volte para o mesmo grupo social,

35 BRASIL. Superior Tribunal de Justiça. Habeas Corpus n²26668 - Distrito Federal. Relatora: Min. Maria Thereza de Assis Moura. Acórdão de 02 de fevereiro de 2012. Disponível em:https://ww2.stj.jus.br/revistaeletronica/ Abre_Documento.asp?sLink=ATC\&sSeq=19966452\&sReg=201102867757\&sData=20120215\&sTipo=91\&format o=PDF. Acesso em: 01 nov. 2012.

36 BRASIL. Superior Tribunal de Justiça. Habeas Corpus n 194967 - Minas Gerais. Relator: Min. Haroldo Rodrigues. Acórdão de 02 de agosto de 2012. Disponível em: https://ww2.stj.jus.br/revistaeletronica/Abre_Documento.a sp?sLink=ATC\&sSeq=16258619\&sReg=201100119625\&sData=20110822\&sTipo=51\&formato=PDF. Acesso em: 01 nov. 2012. 
familiar e de amizades que o tornavam propenso ao crime. Assim, no HC 227406$\mathrm{SP}$, a ministra relatora entendeu que "a vulnerabilidade do adolescente, que anteriormente se envolveu reiteradamente em atos infracionais graves, demonstra que ele necessita de um acompanhamento mais efetivo" ${ }^{\prime 37}$. Da mesma maneira, o HC 231928-SP:

[...] a determinação da medida socioeducativa de semiliberdade foi devidamente fundamentada, tendo sido ressaltada a gravidade concreta do ato infracional praticado e as circunstâncias pessoais do menor infrator, a evidenciar a sua situação de vulnerabilidade, elementos que, somados, justificam a imposição de medida socioeducativa mais rigorosa, nos termos do art. $112, \S 1^{\circ}$, do Estatuto da Criança e do Adolescente $^{38}$.

Se até aqui a vulnerabilidade aparecia como característica ensejadora da medida de privação de liberdade para contenção e acompanhamento, no HC 235878 a ministra relata sob qual justificativa a decisão de denegação da ordem de Habeas Corpus no Tribunal de origem ocorreu: "Desta forma, a medida de internação é aquela que melhor se coaduna com a necessidade de correta proteção da recorrente, sendo a mais eficaz para proporcionar à jovem melhor readaptação ao convívio social, ao contrário de qualquer outra medida, que permitirá sua permanência nas ruas, facilitando o cometimento de novos atos infracionais" 39 . Aparece aqui claramente a perspectiva tutelar que entende a proteção como restrição de direitos determinada pelo juiz em favor do adolescente. Tem-se aí uma verdadeira e comum contradição: como pode uma medida que retira direitos ser considerada um bem ao adolescente?

Isso só pode ser entendido segundo a ótica da situação irregular, que tornava indiferenciados o abandonado e o delinquente, dado que a origem do segundo é o primeiro e o destino do primeiro é o segundo. Como observa Baratta, a droga ou os crimes contra o patrimônio, ou mesmo a mera situação de abandono, são

37 BRASIL. Superior Tribunal de Justiça. Habeas Corpus n 227406 - São Paulo. Relatora: Min. Laurita Vaz. Acórdão de 21 de junho de 2012. Disponível em: https://ww2.stj.jus.br/revistaeletronica/Abre_Documento.asp?sLink $=$ ATC\&sSeq=22715396\&sReg=201102942164\&sData=20120629\&sTipo=91\&formato=PDF. Acesso em: 01 nov. 2012.

38 BRASIL. Superior Tribunal de Justiça. Habeas Corpus n 180575- Minas Gerais. Relator: Min. Sebastião Reis Júnior. Acórdão de 17 de novembro de 2011. Disponível em: https://ww2.stj.jus.br/revistaeletronica/Abre_Documento.asp?sLink=ATC\&sSeq=18542727\&s Reg=201001384097\&s Data=20111214\&sTipo=51\&formato=PDF. Acesso em: 01 nov. 2012.

39 BRASIL. Superior Tribunal de Justiça. Habeas Corpus n 180575- Minas Gerais. Grifou-se. 
as situações que criam a ocasião para que o sistema recrute o jovem, de maneira que mesmo com todas as mudanças ele permanece substancialmente o mesmo: "a criminalização das crianças e adolescentes pobres pela única razão de serem pobres e de se encontrarem em 'situação irregular'"40.

O paradigma da situação irregular com a sua abordagem biopsicossocial e de características deterministas, ao ligar a trajetória do abandono à delinquência, somente se coaduna com uma criminologia etiológica. A criminologia crítica se aproxima da doutrina da proteção integral, compreendendo a criança e o adolescente como sujeitos de direitos e não como objetos de tutela, e que têm a liberdade como um de seus direitos mais fundamentais. Daí que não se sustenta a ideia de privação de liberdade para proteção, nem tampouco a ideia de ressocialização por meio dela, seja pela sua impossibilidade, seja pela compreensão de que isso seria uma violência à sua liberdade.

Além disso, a educação é um direito da criança e do adolescente, que deve ser garantido por meio de políticas sociais. Ao defender a privação da liberdade como meio para garantir o direito à educação do adolescente por meio de uma política de controle social, o que se faz é utilizar uma argumentação politicamente correta para mascarar a realidade: o sistema penal não tem a finalidade de educar, mas a de punir seletivamente os autores de determinados tipos de ilegalidades.

No segundo grupo de julgados constam apenas dois, cujo entendimento coincide na identificação da vulnerabilidade do adolescente, também sem indicar em relação a que, mas como ensejadora de medida protetiva e não de privação da liberdade. O primeiro caso é o de uma adolescente grávida e usuária de drogas já condenada ao cumprimento de medida socioeducativa de internação em primeiro e segundo graus. A ministra, por outro lado, adota o seguinte entendimento:

Na espécie, embora a paciente tenha respondido por outro ato de mesma natureza, não há reiteração. No tocante à situação de vulnerabilidade social em que se encontra a adolescente (estado gravídico e uso de entorpecentes), faz-se necessário observar as medidas protetivas elencadas no art. 101 do aludido Estatuto ${ }^{41}$.

40 BARATTA, Alessandro. Prefácio. In: BATISTA, Vera Malaguti. Difíceis ganhos fáceis: Drogas e juventude pobre no Rio de Janeiro. Rio de Janeiro: Revan, 2003. p. 18.

41 BRASIL. Superior Tribunal de Justiça. Habeas Corpus n² 235878- Rio de Janeiro. Relatora: Min. Maria Thereza 
É interessante notar que em primeiro grau a decisão foi de que a situação de vulnerabilidade justificaria a "proteção" da adolescente por meio da "grave restrição de liberdade" da medida de internação.

Com o mesmo entendimento, no HC 231928 a ministra buscou esclarecer que

Não é razoável restringir o direito de liberdade, amparando-se na condição de vulnerabilidade. Isto porque tal situação fática não autoriza a medida de internação, que só poderá ser infligida inexistindo outra mais adequada e, ainda, quando cumpridas as condições elencadas no art. 122 do ECA. Tal quadro conduz, antes, à aplicação de medidas protetivas (art. 101 do ECA $)^{42}$.

Nessas duas decisões da mesma ministra, percebe-se uma interpretação oposta às anteriores, diferenciando, de um lado, a restrição da liberdade da proteção; e, de outro lado, a vulnerabilidade da periculosidade. Depreende-se da decisão que a vulnerabilidade, nesse caso, demonstraria ser o adolescente vítima de um contexto social, cabendo ao Estado proteger e não punir. Contudo, é importante verificar que a primeira categoria de julgados foi massivamente preponderante em relação à segunda, demonstrando a opção pela definição de vulnerabilidade como uma situação pessoal e social ligada ao indivíduo que determina a ausência de condições de viver em sociedade sem afrontar as normas. Por isso, adota-se a aplicação das medidas socioeducativas de semiliberdade e de internação em um sentido mesmo de contenção, para evitar que os adolescentes retornem às suas famílias desestruturadas ou às más companhias. Para tanto, justificam-se com o uso das ideias de prevenção especial, seja como proteção, seja como oportunidade de estudo e profissionalização do adolescente. Nota-se, porém, que o sentido parece ser mais de defesa social do que qualquer outra coisa.

de Assis Moura. Acórdão de 25 de junho de 2012. Disponível em: https://ww2.stj.jus.br/revistaeletronica/Abre_Documento.asp?sLink=ATC\&sSeq=23001465\&sReg=201200503766\&sData=20120629\&sTipo=91\&formato=PDF. Acesso em: 01 nov. 2012.

42 BRASIL. Superior Tribunal de Justiça. Habeas Corpus n 231928- São Paulo. Relatora: Min. Maria Thereza de Assis Moura. Acórdão de 10 de abril de 2012. Disponível em: https://ww2.stj.jus.br/revistaeletronica/Abre_Documento.asp?sLink=ATC\&sSeq=21452204\&sReg=201200178268\&sData=20120423\&sTipo=91\&formato=PDF. Acesso em: 01 nov. 2012. 


\section{DA VULNERABILIDADE SOCIAL À VULNERABILIDADE PERANTE O SISTEMA DE CONTROLE PENAL}

Vulnerabilidade é um desses termos utilizados de maneira corriqueira que, no entanto, não passaram pelo crivo do questionamento sobre o que é e para que serve. Como observa Uriarte, o termo periculosidade foi proscrito pela doutrina da proteção integral, dando margem ao uso excessivo dos termos vulnerabilidade e contenção para lidar com os adolescentes por meio de suas condições pessoais e sociais ${ }^{43}$.

O foco do sistema penal nos pobres é uma consequência da relação determinista entre pobreza e criminalidade, resultado de preconceitos sociais que moveram os estudos do positivismo criminológico no século XIX. Isso pode ser visualizado nos crimes cometidos por aqueles que são controlados pelo sistema penal, seja ele voltado aos adultos, seja ele voltado aos adolescentes. Quando verificados tanto os dados de encarceramento quanto os dados de adolescentes internados, nota-se que na sua maior parte os indivíduos foram privados de sua liberdade em razão de crimes contra o patrimônio e tráfico de drogas. O sistema penal, em interação com as agências de controle social informal, a partir dos processos de criminalização primária e secundária, determina quem serão as pessoas consideradas desviantes em uma determinada sociedade.

Diferentemente do que se quer fazer crer cotidianamente com a criminalização de adolescentes, assim como na esfera adulta, a prática de atos infracionais por membros daquele grupo é a regra, e não a exceção ${ }^{44}$. O fato de apenas alguns adolescentes caírem nas malhas do sistema penal redunda em uma seletividade característica de todos os sistemas penais. A parcela mais significativa dos atos infracionais praticados pela juventude em geral é tolerada, resolvida por meio de medidas alternativas adotadas pela família e pelo grupo social do qual o jovem faz parte, configurando a cifra obscura dos atos infracionais.

43 URIARTE, Carlos E. Vulnerabilidad, privación de libertad de jóvenes y derechos humanos.

44 SANTOS, Juarez Cirino dos. O adolescente infrator e os direitos humanos. Discursos sediciosos: crime, direito e sociedade, ano 5 , n. 9 e $10,1^{\circ}$ e $2^{\circ}$ sem. 2000, p. 169-179. 
Isso significa que as expressões "adolescente infrator" ou mesmo "adolescente autor de ato infracional" não são exatas: se na prática todos ou quase todos os adolescentes praticam atos contrários à legislação penal, o que os distingue exatamente é o fato de uns terem sido rotulados como tais pelo próprio sistema de justiça juvenil e outros não, por consequência de terem sido ou não recrutados pelo sistema penal ${ }^{45}$.

O que determina essa seletividade torna-se, então, a grande questão: ela se dá ao acaso, ou está prioritariamente voltada contra alguns jovens mais do que contra outros? De fato, o número de crianças e jovens de classe baixa e não brancos que chegam ao sistema de justiça é muito maior do que os de classe média e média alta ${ }^{46}$. Aí aparece o resultado da primeira seletividade: a da agência policial. A segunda seletividade aparece ainda mais evidentemente no Judiciário: a remissão e a aplicação de medidas alternativas à privação de liberdade ocorrem prioritariamente para o grupo de adolescentes de classe média e alta, reservandose a internação apenas aos pobres.

Daí que o entendimento sobre o termo vulnerabilidade deva ser radicalmente invertido em relação à forma como utilizada nos julgados analisados. Se todos os adolescentes praticam atos infracionais e o sistema penal não está estruturado para se voltar contra todos eles; se em razão dessa impossibilidade o sistema penal seleciona alguns atos infracionais e algumas pessoas pertencentes a um determinado estereótipo para perseguir; se essa escolha nada tem a ver com a gravidade do ato infracional, mas sim com uma definição estabelecida pelas agências de controle penal, então os adolescentes que praticam o tipo de ato infracional mais perseguido e pertencem ao estereótipo mais visado são efetivamente mais vulneráveis: ao sistema penal. Nas palavras de Zaffaroni,

Diante da absurda suposição - não desejada por ninguém - de criminalizar reiteradamente toda a população, torna-se óbvio que o sistema penal está estruturalmente montado para que a legalidade processual não opere e, sim, para que exerça seu poder com altíssimo grau de arbitrariedade seletiva dirigida, naturalmente, aos setores vulneráveis ${ }^{47}$.

45 SANTOS, Juarez Cirino dos. O adolescente infrator e os direitos humanos.

46 SILVA, Enid Rocha Andrade; GUERESI, Simone. Adolescentes em conflito com a lei: situação do atendimento institucional no Brasil. Brasília: Ipea, 2003.

47 ZAFFARONI, Eugenio Raúl. Em busca das penas perdidas: A perda de legitimidade do sistema penal. Rio de Janeiro: Revan, 1991. p. 25. 
Quando se trata de ato infracional, o conceito de vulnerabilidade mais eficaz de se utilizar se se quer partir de uma perspectiva crítica é o de vulnerabilidade perante o sistema de controle penal. Essa vulnerabilidade é dada pela situação pessoal do indivíduo, mais do que pelos seus atos, mas também por eles, o que implica as maiores chances que tem de ser recrutado pelo sistema. Esse sistema, então, não tem a finalidade de reduzir a vulnerabilidade, mas sim de reproduzila. A privação da liberdade, ao contrário de produzir o efeito de redução da vulnerabilidade, conforme parece ser o entendimento dos ministros autores das decisões analisadas, a reproduz, pois "estreita o espaço de opções do indivíduo e aumenta sua exposição ao sistema penal"48.

Zaffaroni et al. explicam que a vulnerabilidade perante o sistema penal pode ser entendida de duas maneiras: um estado de vulnerabilidade ao poder punitivo, "que depende de sua correspondência com um estereótipo criminal"; e uma situação de vulnerabilidade, "que é a posição concreta de risco criminalizante em que a pessoa se coloca"49. Para se colocar em situação de vulnerabilidade, ou seja, de risco criminalizante, aqueles que correspondem a um estereótipo e, portanto, estão em estado de vulnerabilidade significativo, não precisam se esforçar muito. Ao contrário, quem não se enquadra em um estereótipo precisa esforçar-se muito para se posicionar em situação de risco criminalizante, pois é baixo seu estado de vulnerabilidade ${ }^{50}$.

Nesses casos, relacionados à criminalidade comum praticada por não pertencentes aos estereótipos do criminoso, Zaffaroni et al. os denominam criminalização por comportamento grotesco ou trágico. Já nos casos em que o próprio tipo de crime é daqueles não compreendidos como tais pela sociedade, em especial os crimes de colarinho branco, a criminalização ocorre por falta de cobertura, e "servem também para encobrir ideologicamente a seletividade do sistema, que através de tais casos pode apresentar-se como igualitário" ${ }^{11}$.

48 URIARTE, Carlos E. Vulnerabilidad, privación de libertad de jóvenes y derechos humanos. $p$. 104.

49 ZAFFARONI; E. Raúl; BATISTA, Nilo et al. Direito penal brasileiro. v. I. 2. ed. Rio de Janeiro: Revan, 2003. p. 49.

50 ZAFFARONI; E. Raúl ; BATISTA, Nilo et al. Direito penal brasileiro. v. I.

51 ZAFFARONI; E. Raúl; BATISTA, Nilo et al. Direito penal brasileiro. v. I. 2. ed. Rio de Janeiro: Revan, 2003. p. 49. 
Assim, a vulnerabilidade relatada pelos ministros em suas decisões parajustificar a aplicação de medidas socioeducativas mais duras é muito mais relacionada às chances que esses adolescentes tinham de ser perseguidos pelo sistema penal e efetivamente chegar ao Judiciário, do que a uma condição que os leva a praticar mais atos infracionais do que outros.

Não se nega com essa abordagem que efetivamente os adolescentes estejam passando por situações de repressão de suas necessidades humanas fundamentais. De fato, aqueles que sofrem a violência estrutural costumam ser os primeiros a padecer de todas as outras formas de violência, dentre as quais aparece a violência institucional ${ }^{52}$. O que se não admite, porém, é que essa situação de vulnerabilidade seja pessoalmente atribuída a esses indivíduos e valorada em seu prejuízo, sem questionar o quanto as próprias agências de controle protagonizam a sua construção social.

Não se nega também a realidade do cometimento do ato infracional. Contudo, a escolha de alguns atos infracionais a perseguir, os lugares onde procurar e os figurinos a buscar determinam, diretamente, que algumas pessoas possuem muito mais chances de virem a ser selecionadas do que outras. $E$, ao fazer ingressar o adolescente no sistema, suas já fracas chances de sair da situação de vulnerabilidade perante o sistema de controle se reduzem drasticamente.

Dessa maneira, o uso da vulnerabilidade como estratégia discursiva para legitimar a intervenção de um sistema que se presta apenas à punição e à reprodução das desigualdades sociais se mostra arbitrário e incompatível com o paradigma da proteção integral. Aparece aqui claramente o paradigma da ambiguidade, de que fala García Méndez: se, por um lado, os juízes aceitam a mudança de paradigma em teoria para proclamar que os adolescentes têm direitos, por outro lado, não a aceitam em suas últimas consequências ${ }^{53}$. Mantém-se, assim, a perspectiva menorista, com todo o seu conteúdo lombrosiano e principalmente com a admissibilidade de um enorme poder discricionário, dentro de um sistema inquisitório, que se já não mais admite no sistema penal adulto. A vulnerabilidade, da forma como utilizada no 52 BARATTA, Alessandro. Derechos humanos: entre violencia estructural y violencia penal. Por la pacificación de los conflictos violentos. In: ELBERT, Carlos Alberto. Criminología y sistema penal: Compilación in memorian. p. 334-356. Montevideo/Buenos Aires: B de F, 2004. 
tema do ato infracional, especialmente no Judiciário, é uma construção social que legitima a adoção de posturas que, a pretexto de serem protetivas, são, na verdade, discricionárias e repressivas.

A partir dessa constatação, observa-se a necessidade de superação do paradigma etiológico em criminologia quando se trata do direito da criança e do adolescente para chegar a uma perspectiva crítica que leve em consideração a necessidade de se mitigar a vulnerabilidade do adolescente perante o sistema penal, bem como sua seletividade. Dado que essa seletividade é estrutural e não meramente conjuntural, nada resta senão minimizar esse sistema punitivo deslegitimado, junto com todas as fantasias que utiliza para travestir-se: de proteção, de educação, de ressocialização. Se há algo de produtivo em todos os sistemas disciplinares, em especial no sistema penal - seja ele adulto ou juvenil -, seu produto é aquilo que ele persegue: o delinquente.

\section{CONSIDERAÇÕES FINAIS}

A seletividade é um atributo do sistema penal já bem conhecido daqueles que buscam compreender o seu funcionamento. $O$ fato de que esse sistema atue a partir da escolha de alguns crimes dentre os tantos cometidos e apenas de alguns autores costuma ser um tipo de denúncia que demonstra a sua seletividade. $\mathrm{O}$ discurso jurídico-penal, contudo, se baseia na ideia de igualdade perante a lei e de respeito às garantias, negando que essa constatação seja uma sua característica estrutural. Ao contrário, na área da criança e do adolescente, realidade e discurso jurídico parecem caminhar na mesma direção: a seletividade do sistema penal, voltado quase exclusivamente aos pobres e não brancos, é confirmado no discurso sob alguns eufemismos, sobretudo de proteção, educação e ressocialização.

Este trabalho buscou analisar a relação aparentemente já naturalizada entre a identificação de situações de vulnerabilidade pessoal e social e a restrição de liberdade de adolescentes no sistema de justiça da infância e da juventude no Brasil. Por isso, partiu-se de uma análise histórica para compreender a primeira relação efetuada nesse sentido: aquela que identificava abandono e infração e 
dava às duas situações a mesma solução, a privação da liberdade. Desde o início do século $X X$, quando ingressou no país a perspectiva tutelar, toda a legislação destinada ao público jovem foi ela própria seletiva: voltada não a todas as crianças e adolescentes, mas aos menores. A figura do menor simboliza bem esse paradigma. Identifica-se a causa do problema do menor na marginalização social, incluindose, então, como potenciais infratores da lei, portadores de desvio de conduta ou de conduta antissocial apenas aqueles que se identificam ao estereótipo do marginalizado. Assim, a imunização dos jovens não pertencentes a esse estereótipo não trazia uma contradição entre teoria e prática, mas sim confirmava a teoria: as políticas de controle explicitavam essa seletividade ao proclamarem que o problema do menor era um problema de marginalização social.

Com a mudança de paradigma na legislação brasileira da doutrina da situação irregular para a doutrina na proteção integral, muito se modificou em termos teóricos. Na prática, contudo, os órgãos mantêm a perspectiva menorista, legitimando a seletividade de sempre. Seja em razão do clássico deficit de políticas sociais no Brasil, seja por uma crise político-cultural ${ }^{54}$, o que se vê no senso comum a respeito da criança e do adolescente é, de um lado, a reprodução do menorismo, baseado na criminologia positivista e, de outro lado, a ascensão de um punitivismo exacerbado.

Um exemplo é a questão da vulnerabilidade, escolhida para ser o objeto de análise deste trabalho. A vulnerabilidade não existe ontologicamente, ela existe em relação a algo. Crianças e adolescentes podem ser vulneráveis, por exemplo, aos adultos, ou mesmo ao sistema de controle penal. Tal vulnerabilidade, contudo, ao ser reconhecida pelos tribunais, vem sendo utilizada em seu desfavor, entendendo que é ela um dado e que a intervenção do sistema penal pode servir para conter tal situação. A crítica realizada neste artigo aponta para a necessidade de inversão dessa lógica: se o sistema é autodeclarado seletivo, de maneira que os jovens pertencentes ao estereótipo de autor de ato infracional possuem chances elevadíssimas de serem controlados pelo sistema, enquanto outros também por

54 GARCÍA MENDEZ, Emilio. Adolescentes y responsabilidad penal: un debate latino-americano. In: Congreso Internacional de Derecho Penal. Ciudad de México: Centro de Investigaciones jurídicas, UNAM, 2006. Disponível em: http://www.juridicas.unam.mx/sisjur/ penal/pdf/11-566s.pdf. Acesso em: 13 set. 2012. 
serem e parecerem o que são precisam se esforçar muito para serem recrutados, então é a vulnerabilidade em relação ao sistema penal que deve ser objeto de análise em casos de ato infracional, e não o contrário.

O trabalho conclui com a necessidade de efetiva redução da vulnerabilidade dos clientes preferenciais por meio de duas principais linhas: primeiro, a minimização do sistema infracional na área da infância e da juventude, que apenas vulnera direitos e somente protege aqueles que imuniza; segundo, a busca por alavancar as políticas sociais voltadas a esse grupo social, garantindo os direitos que são diariamente desrespeitados, de maneira a acabar com a hipocrisia do discurso tutelar. Além disso, não se pode deixar de lado a situação daqueles já selecionados pelo sistema e que a cada dia se tornam mais vulneráveis a ele. Em relação a esses, deve-se buscar retomar a ideia de reintegração social por meio da diminuição da privação de liberdade e a criação de mecanismos institucionais e comunitários que possibilitem a esses adolescentes ter minimizada a sua situação de vulnerabilidade ao sistema penal.

\section{REFERÊNCIAS}

ARIÉS, Philippe. História social da criança e da família. Tradução de Dora Flaksman. 2. ed. LTC, 1981.

BARATTA, Alessandro. Derechos humanos: entre violencia estructural y violencia penal. Por la pacificación de los conflictos violentos. In: ELBERT, Carlos Alberto. Criminología y sistema penal: Compilación in memorian. p. 334-356. Montevideo/Buenos Aires: B de F, 2004.

BARATTA, Alessandro. Prefácio. In: BATISTA, Vera Malaguti. Difíceis ganhos fáceis: Drogas e juventude pobre no Rio de Janeiro. Rio de Janeiro: Revan, 2003.

BRASIL. Decreto n. 847 de 11 de outubro de 1890. Promulga o Código Penal. Disponível em: http://www.planalto.gov.br/ccivil_03/decreto/1910-1929/D17943Aimpressao.htm. Acesso em: 24 ago. 2012.

BRASIL. Decreto n 17.943-A de 12 de outubro de 1927. Consolida as leis de assistencia e protecção a menores. Disponível em: http://www.planalto.gov. br/ccivil_03/decreto/19101929/D17943Aimpressao.htm. Acesso em: 24 ago. 2012. 
BRASIL. Lei $\mathbf{n}^{\circ} \mathbf{6 . 6 9 7}$, de 10 de outubro de 1979. Institui o Código de Menores. Disponível em: http://www.planalto.gov.br/ccivil_03/leis/1970-1979/L6697impressao.htm. Acesso em: 25 ago. 2012.

BRASIL. Ministério da Previdência e Assistência Social. Fundação Nacional do Bem-Estar do Menor. O "menor-problema social" no Brasil e a ação da FUNABEM. Rio de Janeiro: MPAS, 1976.

BRASIL. Superior Tribunal de Justiça. Habeas Corpus n ${ }^{180575-~ M i n a s ~ G e r a i s . ~ R e l a t o r: ~ M i n . ~}$ Sebastião Reis Júnior. Acórdão de 17 de novembro de 2011. Disponível em: https://ww2.stj. jus.br/revistaeletronica/Abre_ Documento.asp?sLink=ATC\&sSeq =18542727\&sReg=2010013 84097\&sData $=$ 20111214\&sTipo=51\&formato=PDF. Acesso em: 01 nov. 2012.

BRASIL. Superior Tribunal de Justiça. Habeas Corpus n 194967 - Minas Gerais. Relator: Min. Haroldo Rodrigues. Acórdão de 02 de agosto de 2012a. Disponível em: https://ww2.stj.jus.br/ revistaeletronica/Abre_Documento.asp? sLink=ATC\&sSeq $=16258619 \&$ sReg $=201100119625$ \&sData $=20110822 \&$ sTipo=51\&formato=PDF. Acesso em: 01 nov. 2012.

BRASIL. Superior Tribunal de Justiça. Habeas Corpus n 226668 - Distrito Federal. Relatora: Min. Maria Thereza de Assis Moura. Acórdão de 02 de fevereiro de 2012b. Disponível em: https://ww2.stj.jus.br/revistaeletronica /Abre_Documento.asp?s Link=ATC\&sSeq=19966452\&s Reg $=201102867757 \&$ s Data=20120215\&sTipo=91\&formato=PDF. Acesso em: 01 nov. 2012.

BRASIL. Superior Tribunal de Justiça. Habeas Corpus n²27406 - São Paulo. Relatora: Min. Laurita Vaz. Acórdão de 21 de junho de 2012c. Disponível em: https://ww2.stj.jus.br/ revistaeletronica/Abre_Documento.asp?s Link=ATC\&sSeq=22715396\&sReg=201102942164 \&sData $=20120629 \&$ sTipo=91\&formato=PDF. Acesso em: 01 nov. 2012.

BRASIL. Superior Tribunal de Justiça. Habeas Corpus n 231928- São Paulo. Relatora: Min. Maria Thereza de Assis Moura. Acórdão de 10 de abril de 2012d. Disponível em: https://ww2. stj.jus.br/revistaeletronica/Abre_Documento. asp? sLink=ATC\&sSeq=21452204\&sReg=2012 00178268\&sData=20120423\&s Tipo=91\&formato=PDF. Acesso em: 01 nov. 2012.

BRASIL. Superior Tribunal de Justiça. Habeas Corpus n 235878- Rio de Janeiro. Relatora: Min. Maria Thereza de Assis Moura. Acórdão de 25 de junho de 2012e. Disponível em: https:// ww2.stj.jus.br/revistaeletronica/Abre_ Documento.asp? sLink=ATC\&sSeq=23001465\&sReg= 201200503766\&sData = 20120629\&sTipo=91\&formato=PDF. Acesso em: 01 nov. 2012.

BRASIL. Superior Tribunal de Justiça. Habeas Corpus n 238756 - Distrito Federal. Relator: Min. Marco Aurélio Bellizze. Acórdão de 28 de agosto de 2012f. Disponível em: https://ww2. stj.jus.br/revistaeletronica/AbreDocumento .asp?sLink $=$ ATC \&sSeq $=23808048 \&$ sReg $=201200$ 713402\&sData=20120920\&sTipo=5\&formato= PDF. Acesso em: 01 nov. 2012. 
BUDÓ, Marília De Nardin. De vítimas a bandidos: o caráter equívoco do tratamento da infância e da adolescência nos projetos lei propostos na Câmara dos Deputados. In: Anais do IV Seminário Internacional de Sociologia e Política. Curitiba: UFPR, 2012.

CORTÉS MORALES, Julio. A 100 años de la creación del primer Tribunal de Menores y 10 años de la Convención Internacional de los Derechos del Niño: el desafío pendiente. In: UNICEF. Justicia y derechos del niño, n. 9. Santiago, Chile: 2007. p. 143-158.

CUSTÓDIO, André Viana. Teoria da proteção integral: pressuposto para compreensão do direito da criança e do adolescente. Revista do Direito, v. 29, p. 22-43, Santa Cruz do Sul, 2008.

GARCÍA MENDEZ, Emilio. Adolescentes y responsabilidad penal: un debate latino-americano. In: Congreso Internacional de Derecho Penal. Ciudad de México: Centro de Investigaciones jurídicas, UNAM, 2006. Disponível em: http://www.juridicas.unam.mx/sisjur/penal/pdf/11566s.pdf. Acesso em: 13 set. 2012.

GARCÍA MÉNDEZ, Emilio. Infancia, ley y democracia: una cuestión de justicia. In: UNICEF. Justicia y derechos del niño, n. 9. Santiago, Chile: 2007. p. 27-47.

GARCÍA MENDEZ, Emilio; COSTA, Antonio Caros Gomes. Das necessidades aos direitos. São Paulo: Malheiros, 1994.

KULAITIS, Letícia Figueira Moutinho. Entre a vitimização e a criminalização: a juventude como foco das políticas de segurança pública. In: Anais do IV Seminário Internacional de Sociologia e Política. Curitiba: UFPR, 2012.

LOMBROSO, Cesare. O homem delinqüente. São Paulo: Ícone, 2007.

LONDOÑO, Fernando Torres. A origem do conceito menor. In: DEL PRIORE, Mary (org.). História da criança no Brasil. São Paulo: Contexto, 1991. p. 129-145.

LONGO, Isis S. Da legislação menorista ao ECA: mudanças e permanências nos discursos e imaginário sobre a conduta infanto-juvenil. Anais do Seminário Educação 2009. 17. ed. Políticas educacionais: cenários e projetos sociais. Disponível em: http://www.ie.ufmt.br/ semiedu2009/gts/gt8/ ComunicacaoOral/ISIS\%20SOUSA\%20LONGO.pdf. Acesso em: 29 ago. 2012.

MIRAGLIA, Paula. Aprendendo a lição: uma etnografia das Varas Especiais da Infância e da Juventude. Novos Estudos, n. 72, jul. 2005. p. 79-98. 
MORAES, Pedro Rodolfo Bodê de;PESCAROLO, Joyce Kelly. Quem tem medo dos jovens? Disponível em: http://www.naoviolencia.org.br/pdf/ quemtemedodosjovens.pdf. Acesso em: 20 ago. 2012.

OLIVEIRA, Walter F. de. Educação social de rua: bases históricas, políticas e pedagógicas. História, Ciências, Saúde. Manguinhos, Rio de Janeiro, v. 14, n.1, p.135-158, jan.-mar. 2007. PASSETTI, Edson. O menor no Brasil republicano. In: DEL PRIORE, Mary (Org.). História da criança no Brasil. São Paulo: Contexto, 1991. p. 146-175.

RIZZINI, Irene. O século perdido: Raízes históricas das políticas públicas para a infância no Brasil. 2. ed. rev. São Paulo: Cortez, 2008.

RIZZINI, Irene; RIZZINI, Irma. A institucionalização de crianças no Brasil: Percurso histórico e desafios do presente. Rio de Janeiro: PUC-Rio; São Paulo: Loyola, 2004.

SANTOS, Benedito Rodrigues dos. 18 anos de ECA: a inclusão de crianças e adolescentes no estado de direitos brasileiro, Inclusão social, Brasília, v. 2, n. 2, p. 152-154, abr.-set. 2007.

SANTOS, Juarez Cirino dos. O adolescente infrator e os direitos humanos. Discursos sediciosos: crime, direito e sociedade, ano 5, n. 9 e 10, $1^{\circ}$ e $2^{\circ}$ sem. 2000, p. 169-179.

SANTOS, Marco Antonio Cabral dos. Criança e criminalidade no início do século. In: DEL PRIORE, Mary (Org.). História das crianças no Brasil. São Paulo: Contexto, 1999. p. 210-230.

SILVA, Enid Rocha Andrade; GUERESI, Simone. Adolescentes em conflito com a lei: situação do atendimento institucional no Brasil. Brasília: Ipea, 2003.

URIARTE, Carlos E. Vulnerabilidad, privación de libertad de jóvenes y derechos humanos. Montevideo: Fundación de Cultura Universitaria, 2006.

WAISELFISZ, Julio Jacobo. Mapa da violência 2012: os novos padrões da violência homicida no Brasil. São Paulo: Sangari, 2011. Disponível em: www.mapadaviolência.org.br. Acesso em: 26 jul.2012.

ZAFFARONI, Eugenio Raúl. Em busca das penas perdidas: A perda de legitimidade do sistema penal. Rio de Janeiro: Revan, 1991.

ZAFFARONI; E. Raúl; BATISTA, Nilo et al. Direito penal brasileiro. v. I. 2. ed. Rio de Janeiro: Revan, 2003.

Recebido em: mar/2015

Aprovado em: ago/2015 